\title{
An Aggravated Trajectory of Depression and Anxiety Co-morbid with Hepatitis C: A Within-groups Study of 61 Australian Outpatients
}

\author{
Benjamin J.R. Stewart ${ }^{1, *}$, Deborah Turnbull ${ }^{1}$, Antonina A. Mikocka-Walus ${ }^{2}$, Hugh Harley ${ }^{4}$ \\ and Jane M. Andrews ${ }^{3,4}$
}

${ }^{I}$ School of Psychology, University of Adelaide, Australia; ${ }^{2}$ Department of Health Sciences, University of York, United Kingdom; ${ }^{3}$ Department of Gastroenterology and Hepatology, Royal Adelaide Hospital, Australia; ${ }^{4}$ Discipline of Medicine, University of Adelaide, Australia

\begin{abstract}
Background: This study aimed to explore the course of depression and anxiety in chronic hepatitis C patients. Methods: Data were combined from two studies: (1) Hospital Anxiety and Depression Scale (HADS) scores in 395 consecutive Australian outpatients from 2006 to 2010 formed the baseline measurement; and (2) Depression Anxiety Stress Scales (DASS) scores in a survey of a sub-sample of these patients in 2011 formed the follow-up measurement. After converting DASS to HADS scores, changes in symptom scores and rates of case-ness $(\geq 8)$, and predictors of follow-up symptoms were assessed. Results: Follow-up data were available for 61 patients $(70.5 \%$ male) whose age ranged from 24.5 to 74.6 years $(\mathrm{M}=45.6)$. The time to follow-up ranged from 20.7 to 61.9 months $(\mathrm{M}=43.8)$. Baseline rates of depression $(32.8 \%)$ and anxiety $(44.3 \%)$ increased to $62.3 \%$ and $67.2 \%$, respectively. These findings were confirmed, independent of the conversion, by comparing baseline HADS and follow-up DASS scores with British community norms. Baseline anxiety and younger age predicted depression, while baseline anxiety, high school non-completion, and single relationship status predicted anxiety. Conclusion: This study demonstrated a worsening trajectory of depression and anxiety. Further controlled and prospective research in a larger sample is required to confirm these findings.
\end{abstract}

Keywords: Anxiety, depression, hepatitis C, prognosis, trajectory.

\section{INTRODUCTION}

Psychiatric co-morbidity is prevalent in chronic hepatitis $\mathrm{C}[\mathrm{CHC} ; 1]$ and results in diminished quality of life [2], increased fatigue [3,4] and pain [5], and impaired anti-viral treatment outcomes [6]. It appears that CHC itself may be particularly associated with poorer mental health outcomes, with research showing that the rate of major depression was higher in CHC patients compared with controls or chronic hepatitis B patients [7]. Psychosocial stressors are a contributing factor to this morbidity, and include the adverse effect of diagnosis, anti-viral treatment, stigma, and fears regarding disease progression or viral transmission [8]. Research has demonstrated poorer quality of life in people aware of their CHC infection compared with those unaware $[9,10]$. Thus, the ability of patients to adjust to, and cope with, psychosocial stressors accompanying and following the diagnosis of CHC may be critical in determining the longitudinal course of psychiatric disorders. However, little is known about the course of psychiatric co-morbidity in this cohort. This study aimed to assess the course of depression and anxiety symptoms in a cohort of South Australian CHC outpatients of the Royal Adelaide Hospital (RAH) liver clinic.

*Address correspondence to this author at the School of Psychology, University of Adelaide, North Terrace, Adelaide, South Australia 5005, Australia; Tel: +61 88303 3136;

E-mail: benjamin.j.stewart@adelaide.edu.au

\section{MATERIALS AND METHODOLOGY}

\section{Design and Participants}

This within-subjects study combined and compared data collected on a sub-set of CHC outpatients from two previous studies. In the first [11], Hospital Anxiety and Depression Scale [HADS; 12] scores, collected as part of standard clinical care at appointments at the RAH liver clinic from 2006, were analysed to explore the prevalence and predictors of depression and anxiety in 395 consecutive CHC outpatients from 2006-2010. In the second [13], CHC outpatients from this clinic completed a postal survey in late 2011 and early 2012 exploring psychological treatment acceptability, including a measurement with the Depression Anxiety Stress Scales [14]. Data available for participants of both studies $(n=61)$ were collated to assess the level of depression and anxiety at the two points of assessment.

\section{Procedure}

A recent study facilitated a method of converting scores between the HADS and DASS. Covic and colleagues [15] measured depression and anxiety in British and Australian Rheumatoid Arthritis (RA) patients using the HADS and the DASS. Through use of Rasch Analysis, they were able to calibrate the two scales by mapping scores on to a common underlying metric of psychopathology. The present study applied this metric to convert DASS scores at follow-up in 2011 to HADS scores. A cut-off score $\geq 8$ on the HADS was 
used to determine depression or anxiety, in accordance with recommendations [16, 17]. The ethics committees of the RAH and University of Adelaide provided approval for the two studies comprising it the data for this paper. This research was conducted in accordance with the Declaration of Helsinki.

\section{Analysis}

Differences between HADS scores at baseline (T1) and converted HADS scores at follow-up (T2) were compared using repeated samples t-tests. Rates of case-ness at T1 and T2 were compared using McNemar's test. Levels of depression and anxiety were compared against British norms for T1 HADS scores [18] and T2 DASS scores [19], and the discrepancy between effect sizes analysed, in order to provide an assessment of change independent of DASS conversion. Univariate associations with T2 HADS scores were conducted using Pearson's correlation for continuous predictors and independent samples t-tests for categorical predictors. Multivariate associations were tested using linear regression models with hierarchical entry of predictors with a univariate association of $\mathrm{p}<0.05$, with baseline depression and anxiety scores entered at Step 1, and all other predictors at Step 2.

\section{RESULTS}

Socio-demographic and medical data is presented in Table 1. Of the 61 participants for whom $\mathrm{T} 1$ and $\mathrm{T} 2$ data was available, $43(70.5 \%)$ were male. Their age ranged from 24.49 to 74.61 years $(\mathrm{M}=45.61, \mathrm{SD}=10.08)$ and the time between $\mathrm{T} 1$ and $\mathrm{T} 2$ assessments ranged from 20.64 to 61.92 months $(\mathrm{M}=43.80, \mathrm{SD}=12.24)$.

As shown in Table 2, depression and anxiety rates increased by $\mathrm{T} 2$. The odds of developing new depressive caseness by T2 was 10 times higher than the odds of T1 cases going into remission from depression $(p<0.001,95 \%$ CI:2.34-42.78). Similarly, the odds of developing anxiety case-ness by T2 was 4.5 times higher than the odds of remission from anxiety by $\mathrm{T} 2(\mathrm{p}=0.004,95 \% \mathrm{CI}: 1.52-13.30)$. Finally, the odds of developing co-morbidity by T2 was 4 times higher than the odds of remission from co-morbidity by T2 ( $\mathrm{p}=0.004,95 \% \mathrm{CI}: 1.50-10.66)$.

As shown in Fig. (1), the sample as a whole experienced a significant increase in both depression $(t(60)=6.41$, $p<0.001, d=0.82)$ and anxiety $(t(60)=4.08, p<0.001, d=0.52)$ from $\mathrm{T} 1-\mathrm{T} 2$. When analysed based on case-ness at $\mathrm{T} 1$, depression scores increased significantly in patients without baseline case-ness $(t(31)=6.28, p<0.001, d=1.15)$ and with one baseline disorder $(t(10)=2.87, p=0.017, d=0.88)$ but not in those with T1 co-morbidity $(t(17)=1.64, p=0.120, d=0.39)$. Anxiety scores increased significantly in those without baseline case-ness $(t(31)=5.24, p<0.001, d=1.01)$ and remained stable in those with one baseline disorder $(t(10)=0.75$, $p=0.473, d=0.23)$ or T1 co-morbidity $(t(17)=0.53, p=0.605$, $d=0.13)$.

Table 1. Socio-demographic and medical characteristics of patients.

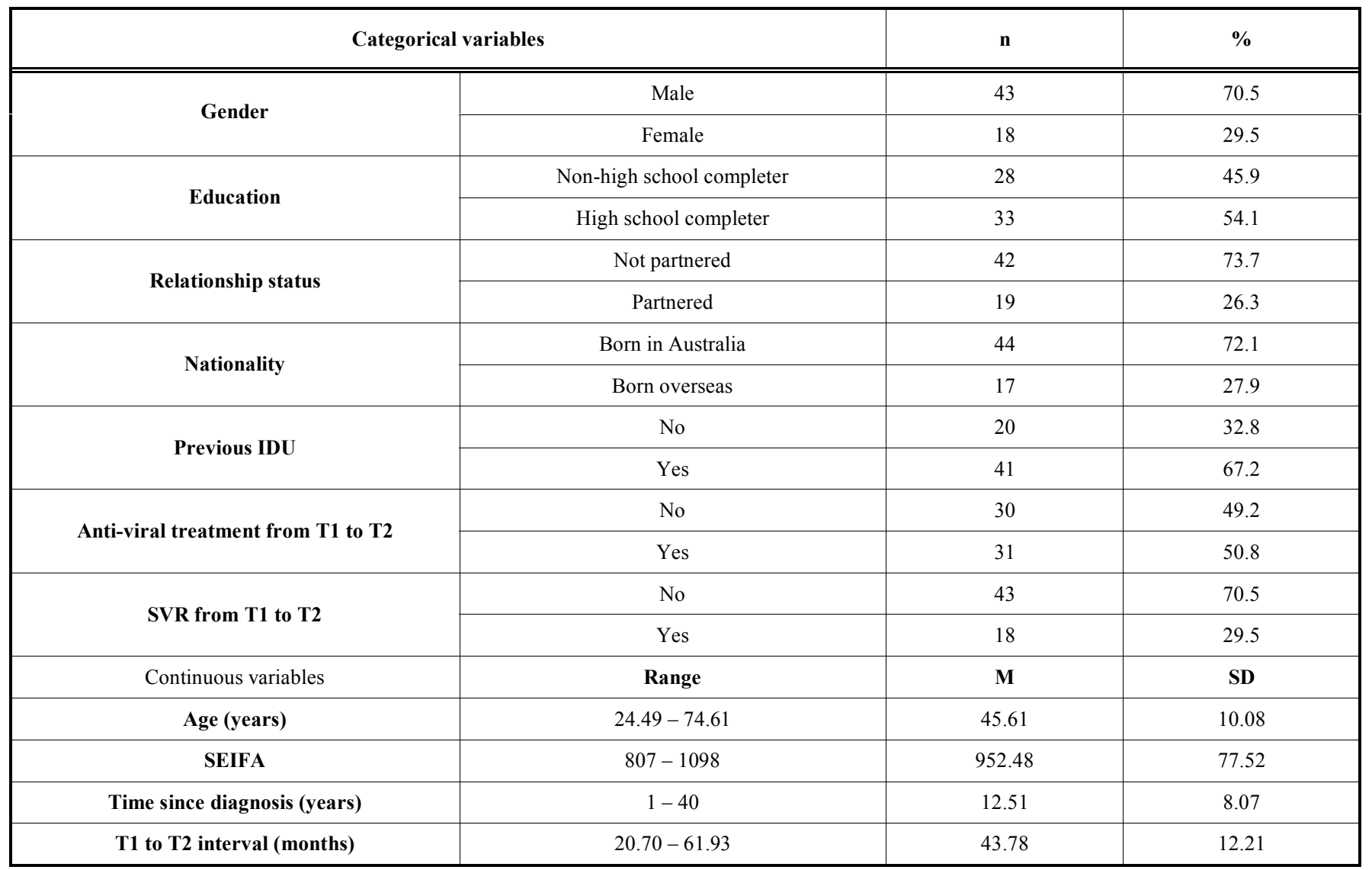

IDU=Injecting drug use, SEIFA=Socio-Economic Index For Areas Index of Advantage/Disadvantage, based on post-code areas. 
Table 2. Depression and anxiety case-ness rates at $\mathrm{T} 1$ and $\mathrm{T} 2$.

\begin{tabular}{|c|c|c|}
\hline \multirow{2}{*}{ Case-ness type } & \multicolumn{2}{|c|}{ Number of cases $\uparrow(\%)$} \\
\cline { 2 - 3 } & Baseline & Follow-up \\
\hline \hline Depression $\uparrow$ & $20(32.8)$ & $38(62.3)$ \\
\hline Depression alone & $2(3.3)$ & $4(8.2)$ \\
\hline Anxiety $\$$ & $27(44.3)$ & $41(67.2)$ \\
\hline Anxiety alone & $9(14.8)$ & $4(13.1)$ \\
\hline Any disorder & $29(47.5)$ & $46(75.4)$ \\
\hline One disorder & $11(18.0)$ & $13(21.3)$ \\
\hline Co-morbid disorders & $18(29.5)$ & $33(54.1)$ \\
\hline
\end{tabular}

† Cases are based on HADS subscale scores $\geq 8 \ddagger$ Cases with 'Depression' or 'Anxiety' may also exhibit case-ness of the other disorder type, as compared with 'Depression alone' or 'Anxiety alone' wherein these cases only exhibit case-ness of that disorder type.

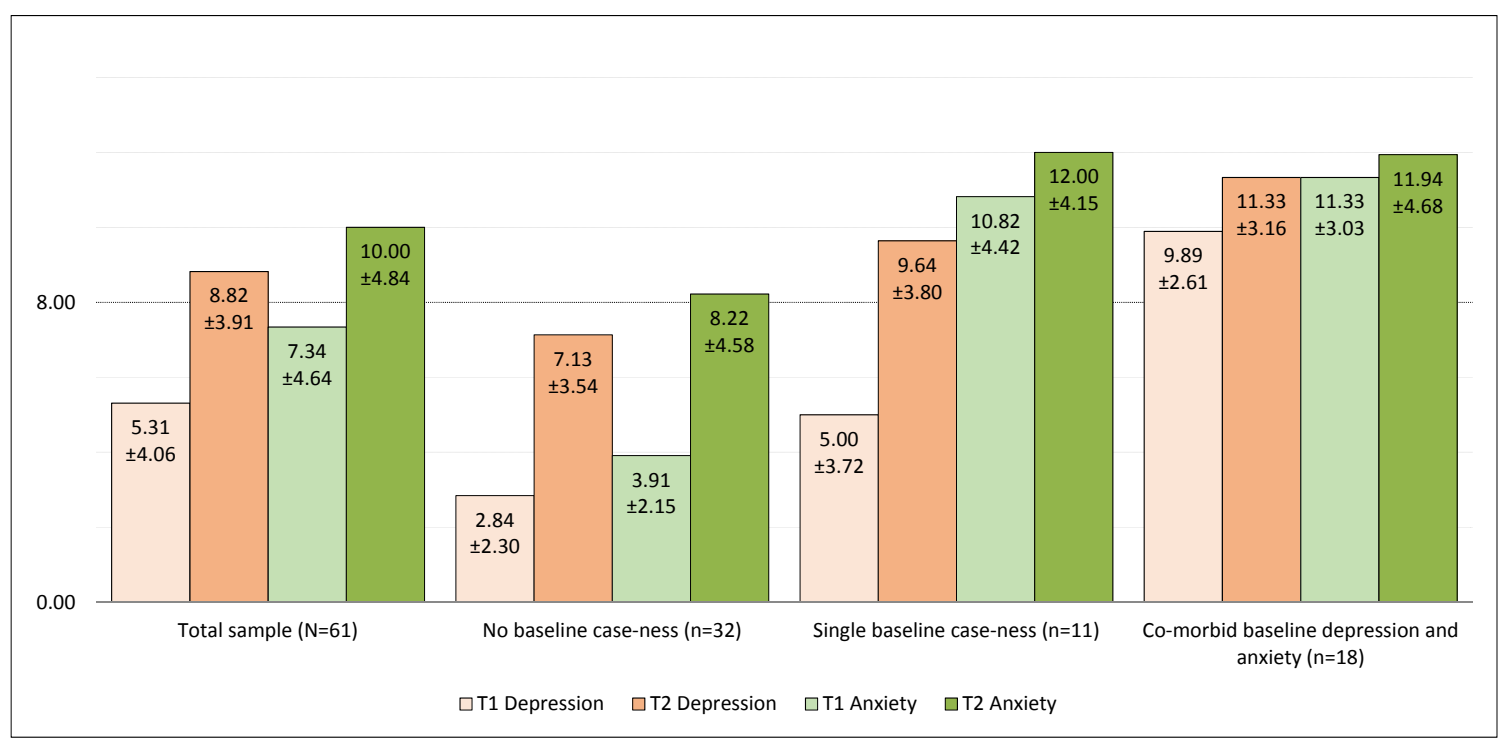

Fig. (1).

As shown in Fig. (2), at T1 the present sample was significantly disadvantaged and was compared to British community HADS norms with respect to both depression $(t(1851)=4.03, \quad p<0.001$, Cohen's $d=0.46)$ and anxiety $(t(1851)=2.43, p=0.015$, Cohen's $d=0.29)$. When DASS scores were compared to British norms at T2, this discrepancy had widened markedly for both depression $(t(1853)=11.83, \quad p<0.001$, Cohen's $d=1.15)$ and anxiety $(t(1853)=12.44, p<0.001$, Cohen's $d=1.16)$.

Univariate predictors of depression and anxiety at T2 were then assessed, including age at T1, gender, nationality, education, the Socio-Economic Index For Areas (SEIFA) relative socio-economic advantage and disadvantage index based on post-code areas at T1 [20], relationship status at T1, previous injecting drug use (IDU), years since diagnosis at $\mathrm{T} 2$, the time between $\mathrm{T} 1$ and $\mathrm{T} 2$ assessments, anti-viral treatment between T1 and T2, achieving an SVR between T1 and $\mathrm{T} 2$, and $\mathrm{T} 1$ anxiety and depression. Depression and anxiety at T1 were significantly and positively correlated with both depression and anxiety scores at T2, while age at T1 was negatively correlated with depression scores at T2. Those
Those who had completed high school and those who were in a relationship at $\mathrm{T} 1$ had significantly lower depression and anxiety scores at $\mathrm{T} 2$.

Significant univariate predictors were then entered into the multivariate analysis, as shown in Table 3. On step 1, T1 depression and anxiety scores were entered. Only anxiety was at $\mathrm{T} 1$ independently predicted both depression and anxiety scores at T2. At step 2, education and relationship status were entered into both models and age was added to the depression model. Age remained significant and explained an additional $11 \%$ of the variance in depression scores at $\mathrm{T} 2$, while education and relationship status remained significant and explained an additional $17 \%$ of the variance in anxiety at $\mathrm{T} 2$.

\section{DISCUSSION}

This study demonstrated a poor trajectory of depression and anxiety in which four groups could be identified: (1) those who were non-cases at both baseline and follow-up $(23.0 \%)$; (2) those who were non-cases at baseline, but 


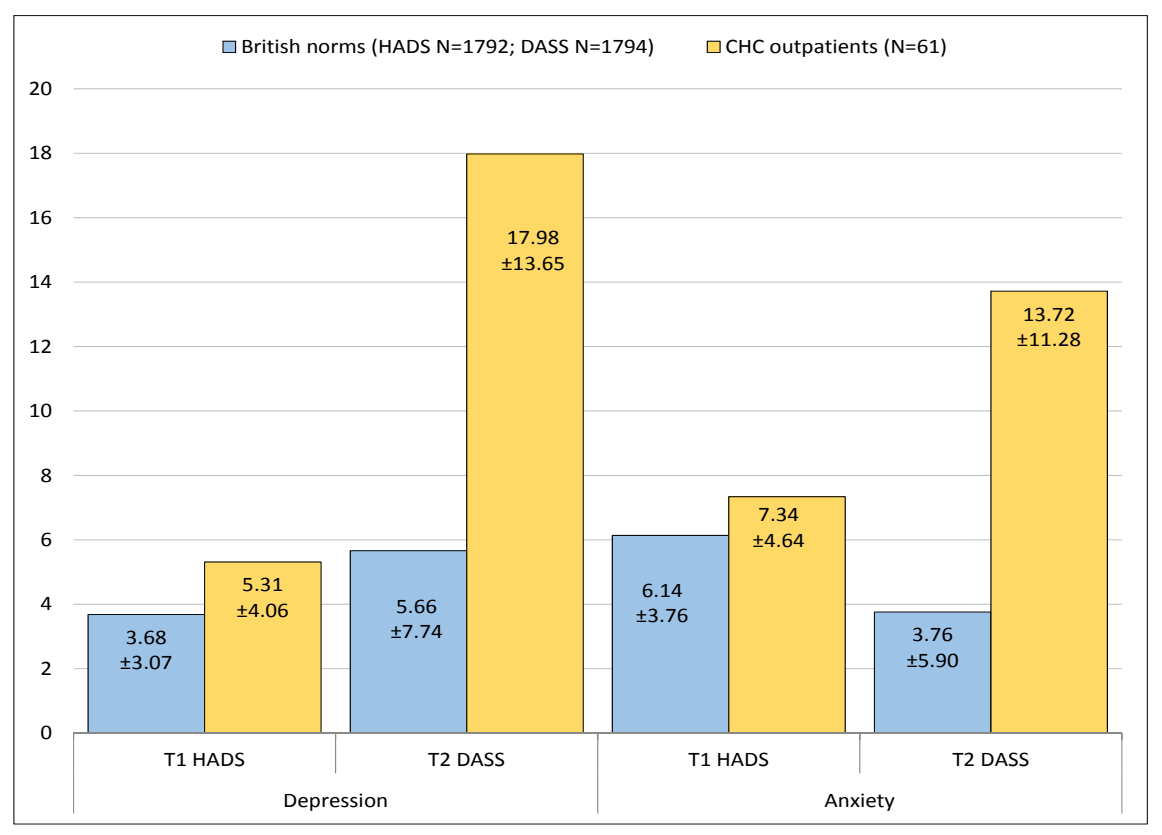

Fig. (2).

Table 3. Multivariate analyses of $\mathrm{T} 2$ depression and anxiety.

\begin{tabular}{|c|c|c|c|c|c|c|c|}
\hline & \multirow{2}{*}{ Variable } & \multicolumn{3}{|c|}{ T2 Depression } & \multicolumn{3}{|c|}{ T2 Anxiety } \\
\hline & & $b$ & $S E b$ & $\beta$ & $b$ & $S E b$ & $\beta$ \\
\hline \multirow{2}{*}{ Step 1} & T1 Depression & 0.15 & 0.15 & .16 & 0.03 & 0.19 & .03 \\
\hline & T1 Anxiety & 0.32 & 0.13 & $.38^{*}$ & 0.41 & 0.16 & $.40^{*}$ \\
\hline \multirow{3}{*}{ Step 2} & T1 Depression & 0.11 & 0.14 & .11 & -0.10 & 0.17 & -.08 \\
\hline & T1 Anxiety & 0.29 & 0.12 & $.35^{*}$ & 0.42 & 0.15 & $.42 * *$ \\
\hline & Age & -0.09 & 0.04 & $-.23 *$ & - & - & - \\
\hline
\end{tabular}

For T2 depression, Step 1 Adjusted $R^{2}=0.22$, Step $2 \Delta R^{2}=0.11(p \mathrm{~s}<0.05)$.

For T2 anxiety, Step 1 Adjusted $R^{2}=0.15$, Step $3 \Delta R^{2}=0.17(p s<0.01)$.

$* \mathrm{p}<0.05, * * \mathrm{p}<0.01$

whose symptoms increased to case-ness thresholds by follow-up (29.5\%); (3) those who were cases at baseline and follow-up (45.9\%); and (4) the sole individual who was a case at baseline and recovered by follow-up (1.6\%). Two studies have also reported worsening in symptoms over time in Crohn's disease [21] and cardiovascular patients [22]. However, these findings contradict the stability reported over one year in two smaller studies with CHC [23, 24]. Moreover, research in other populations have reported stability over time, including in the general population [25] and those with HIV [26, 27], irritable bowel syndrome and inflammatory bowel disease [24, 28], cardiovascular disease [29, 30], and RA [31, 32].
It is possible that the aggravated course observed here can be explained by the differential nature of $\mathrm{CHC}$ and the psychosocial stressors it poses and/or the nature of the populations that typically acquires $\mathrm{CHC}$ - comprising mostly current or former IDUs (67\% in this cohort). Also, previous research has reported a worse prognosis for those with comorbid depression and anxiety [33,34], which is common in CHC patients [1] and, particularly, in the cohort from which this sample was drawn [11].

However, this does not account for the aggravation in those without morbidity at baseline - the group in which the main symptom increase occurred. The correlation between depression and anxiety scores at baseline provides insight 
into the general level of co-morbid symptomatology in the sample regardless of case-ness. In the British community, the correlation between HADS anxiety and depression scores is moderate $(r=0.53, p<0.001)$. In the cohort from which the present sample was drawn [11], the correlation is significantly higher $(r=0.66, \mathrm{Z}=3.63, p<0.001)$, indicating a higher degree of co-morbid symptoms in this patient group.

Interestingly, time since diagnosis was not related to depression or anxiety at follow-up. There was also no association between the change in psychopathology and the variable time difference between the baseline and follow-up assessments across patients. This suggests that the aggravation in symptoms being observed may not be stemming from a failure and to adjust with the diagnosis of $\mathrm{CHC}$ per se or from the mere passage of time. It is possible that the progression observed reflects a difficulty in adjusting to new psychosocial stressors, such as disease progression and treatment considerations. These stressors do not occur at predictable time points following diagnosis, as $\mathrm{CHC}$ can progress quite slowly and patients may present for specialist treatment at different times following diagnosis.

In the multivariate analysis, baseline anxiety, but not depression, remained an independent predictor of both increased depression and anxiety at follow-up. This is supported by longitudinal community-based studies which have found that anxiety leads to depression more often than the reverse [33, 35]. After accounting for baseline depression and anxiety, age remained a significant predictor of decreased depression at follow-up, while education and relationship status remained independent predictors of decreased anxiety - consistent with other research $[25,36]$.

\section{LIMITATIONS}

This study has a number of limitations. There were no control comparison subjects and the length of follow-up varied, due to this studies post-hoc use of routinely collected clinical data as the baseline measurement. While the present cohort was compared with normative data.The sample size was too small to match the age and gender which can influence the expression of mood and anxiety symptoms. Data was not available for whether patients were diagnosed with specific disorders. Symptoms of depression and anxiety can be present across varying mood and anxiety disorders as well as in other psychiatric illnesses including personality and psychotic disorders. It was also not possible to analyse previous or current psychiatric treatment. The sample was small and the participants of the second study who provided follow-up data were self-selected [13], introducing the possibility of sample biases. However, excluding a slightly lower response rate in previous recipients of anti-viral treatment (16\% vs. $25 \%$ ), there were no differences between survey responders and non-responders [13]. Critically, there were no differences in HADS scores. Thus, both non-responders and responders to the survey experienced comparable mental health at baseline. However, it is possible those who experienced a worse course of depression and anxiety after that baseline measurement were more inclined to respond at follow-up because the issue was more personally salient. The multivariate analysis should especially be regarded with caution due to the small sample size and relatively large number of predictor variables are used.
The procedure of converting DASS scores at follow-up with HADS scores to compare symptoms rely on the assumption that the calibration of DASS and HADS scores by Covic and colleagues [15] is robust and equivalent between $\mathrm{RA}$ and $\mathrm{CHC}$ patients. To verify the findings independent of this conversion and its assumptions, baseline HADS and follow-up DASS scores were compared separately to British norms for the HADS [18] and DASS [19], respectively. At baseline, the present sample had significantly worse HADS scores than British norms. However, by follow-up this disadvantage, in comparison to British norms for the DASS, had inflated by a factor of 2.5 for depression and 4 for anxiety.

Finally, subjects who achieved a SVR between baseline and follow-up assessments were included, as many receive ongoing care to assess for viral relapse and manage existing liver damage. If the SVR rates of the sample that provided follow-up data were lower than normal, this could explain their poorer mental health. However, of the 31 patients who received anti-viral treatment, 58\% achieved a SVR, consistent with rates in those treated with interferon and ribavirin [37]. Moreover, SVR was not associated with follow-up depression or anxiety in this study.

\section{CONCLUSION}

This study found a high rate of co-morbid depression and anxiety which increased markedly over a period of up to five years in a small sample of Australian CHC outpatients. Future research would benefit from a controlled, prospective analysis in a larger sample, involving multiple assessments of symptoms and a focus on potential intervening variables such as psychiatric treatment, social support, and changes in $\mathrm{CHC}$ to related psychosocial stressors.

\section{CONFLICT OF INTEREST}

This study did not receive any specific funding from any agency in the public, commercial, or not-for-profit sectors. The authors declare that there is no conflict of interest.

\section{ACKNOWLEDGEMENTS}

We would like to thank Dr. Tanya Covic and Prof. Alan Tennant for their assistance in facilitation the conversion of DASS to HADS scores.

\section{REFERENCES}

[1] El-Serag HB, Kunik M, Richardson P, et al. Psychiatric disorders among veterans with hepatitis C infection. Gastroenterology 2002; 123(2): 476-82.

[2] Gutteling JJ, Duivenvoorden HJ, Busschbach JJV, et al. Psychological determinants of health-related quality of life in patients with chronic liver disease. Psychosomatics 2010; 51(2): 157-65.

[3] Dwight MM, Kowdley KV, Russo JE, et al. Depression, fatigue, and functional disability in patients with chronic hepatitis C. J Psychosom Res 2000; 49(5): 311-7.

[4] McDonald J, Jayasuriya R, Bindley P, et al. Fatigue and psychological disorders in chronic hepatitis C. J Gastroenterol Hepatol 2002; 17(2): 171-6.

[5] Morasco BJ, Huckans M, Loftis JM, et al. Predictors of pain intensity and pain functioning in patients with the hepatitis $C$ virus. Gen Hosp Psychiatry 2010; 32(4): 413-8. 
[6] Leutscher PDC, Lagging M, Buhl MR, et al. Evaluation of depression as a risk factor for treatment failure in chronic hepatitis $\mathrm{C}$. Hepatology 2010; 52(2): 430-5.

[7] Carta MG, Hardoy MC, Garofalo A, et al. Association of chronic hepatitis $\mathrm{C}$ with major depressive disorders: irrespective of interferon-alpha therapy. Clin Pract Epidemiol Ment Health 2007; 3: 22.

[8] Stewart BJ, Mikocka-Walus AA, Harley H, et al. Help-seeking and coping with the psychosocial burden of chronic hepatitis C: a qualitative study of patient, hepatologist, and counsellor perspectives. Int J Nurs Stud 2012; 49(5): 560-9.

[9] Dalgard O, Egeland A, Skaug K, et al. Health-related quality of life in active injecting drug users with and without chronic hepatitis $\mathrm{C}$ virus infection. Hepatology 2004; 39(1): 74-80.

[10] Rodger AJ, Jolley D, Thompson SC, et al. The impact of diagnosis of hepatitis C virus on quality of life. Hepatology 1999; 30(5): 1299-301.

[11] Stewart B, Mikocka-Walus A, Morgan J, et al. Anxiety and depression in Australian chronic hepatitis C outpatients: Prevalence and predictors. Australas Psychiatry 2012; 20(6): 496-500.

[12] Zigmond AS, Snaith RP. The hospital anxiety and depression scale. Acta Psychiatr Scand 1983; 67(6): 361-70.

[13] Stewart BJR, Turnbull D, Mikocka-Walus AA, et al. Acceptability of psychotherapy, pharmacotherapy, and self-directed therapies in australians living with chronic hepatitis C. J Clin Psychol Med Settings $2013 ; 20(4)$ : 427-39.

[14] Lovibond SH, Lovibond PF. Manual for the depression anxiety stress scales. $2^{\text {nd }}$ ed. Sydney, NSW: Psychology Foundation 1995.

[15] Covic T, Cumming SR, Pallant JF, et al. Depression and anxiety in patients with rheumatoid arthritis: prevalence rates based on a comparison of the Depression, Anxiety and Stress Scale (DASS) and the hospital, Anxiety and Depression Scale (HADS). BMC Psychiatry 2012; 12: 6 .

[16] Bjelland I, Dahl AA, Haug TT, Neckelmann D. The validity of the hospital anxiety and depression scale: an updated literature review. J Psychosom Res 2002; 52(2): 69-77.

[17] Fábregas BC, Vitorino FD, Rocha DM, et al. Screening inventories to detect depression in chronic hepatitis C patients. Gen Hosp Psychiatry $2012 ; 34(1): 40-5$.

[18] Crawford JR, Henry JD, Crombie C, et al. Normative data for the HADS from a large non-clinical sample. Br J Clin Psychol 2001; 40(4): 429-34.

[19] Henry JD, Crawford JR. The short-form version of the Depression anxiety stress scales (DASS-21): construct validity and normative data in a large non-clinical sample. Br J Clin Psychol 2005; 44(2): 227-39.

[20] Australian Bureau of Statistics. Information Paper: an introduction to Socio-Economic Indexes for Areas (SEIFA) 2006. Australia: Commonwealth of Australia 2008.

[21] Loftus Jr EV, Guérin A, Yu AP, et al. Increased risks of developing anxiety and depression in young patients with crohn's disease. Am J Gastroenterol 2011; 106(9): 1670-7.

[22] Lane D, Carroll D, Ring C et al. The prevalence and persistence of depression and anxiety following myocardial infarction. $\mathrm{Br} \mathrm{J} \mathrm{H}$ Psychol 2002; 7(1): 11-21.
[23] Kraus MR, Schäfer A, Faller H, et al. Psychiatric symptoms in patients with chronic hepatitis $\mathrm{C}$ receiving interferon alfa- $2 \mathrm{~b}$ therapy. J Clin Psychiatry 2003; 64(6): 708-14.

[24] Mikocka-Walus AA, Turnbull DA, Moulding NT, et al. Does psychological status influence clinical outcomes in patients with inflammatory bowel disease (IBD) and other chronic gastroenterological diseases: an observational cohort prospective study. Biopsychosoc Med 2008; 2: 11.

[25] Bjerkeset O, Nordahl HM, Larsson S, et al. A 4-year follow-up study of syndromal and sub-syndromal anxiety and depression symptoms in the general population. Soc Psychiatry Psychiatr Epidemiol 2008; 43(3): 192-9.

[26] Ickovics JR, Hamburger ME, Vlahov D, et al. Mortality, CD4 cell count decline, and depressive symptoms among HIV-seropositive women: Longitudinal analysis from the HIV epidemiology research study. J Am Med Assoc 2001; 285(11): 1466-74.

[27] Lyketsos CG, Hoover DR, Guccione M, et al. Depressive symptoms over the course of HIV infection before AIDS. Soc Psychiatry Psychiat Epidemiol 1996; 31(3-4): 212-9.

[28] Banovic I, Gilibert D, Cosnes J. Crohn's disease and fatigue: Constancy and co-variations of activity of the disease, depression, anxiety and subjective quality of life. Psychol Health Med 2010; 15(4): 394-405.

[29] Kaptein KI, De Jonge P, Van den Brink RHS, et al. Course of depressive symptoms after myocardial infarction and cardiac prognosis: a latent class analysis. Psychosom Med 2006; 68(5): 662-8.

[30] Smolderen KGE, Aquarius AE, de Vries J, et al. Depressive symptoms in peripheral arterial disease: a follow-up study on prevalence, stability, and risk factors. J Affect Disord 2008; 110(1-2): 27-35.

[31] Smedstad LM, Vaglum P, Moum T, et al. The relationship between psychological distress and traditional clinical variables: a 2 year prospective study of 216 patients with early rheumatoid arthritis. $\mathrm{Br}$ J Rheumatol 1997; 36(12): 1304-11.

[32] Norton S, Sacker A, Young A, Done J. Distinct psychological distress trajectories in rheumatoid arthritis: findings from an inception cohort. J Psychosom Res 2011; 71(5): 290-5.

[33] Fichter MM, Quadflieg N, Fischer UC, et al. Twenty-five-year course and outcome in anxiety and depression in the upper bavarian longitudinal community study. Acta Psychiatr Scand 2010; 122(1): 75-85.

[34] Richards D. Prevalence and clinical course of depression: a review. Clin Psychol Rev 2011; 31(7): 1117-25.

[35] Wetherell JL, Gatz M, Pedersen NL. A longitudinal analysis of anxiety and depressive symptoms. Psychol Aging 2001; 16(2): $187-95$.

[36] Grace SL, Abbey SE, Pinto R, et al. Longitudinal course of depressive symptomatology after a cardiac event: effects of gender and cardiac rehabilitation. Psychosom Med 2005; 67(1): 52-8.

[37] Ghany MG, Nelson DR, Strader DB, et al. An update on treatment of genotype 1 chronic hepatitis $\mathrm{C}$ virus infection: 2011 practice guideline by the American Association for the Study of Liver Diseases. Hepatology 2011; 54(4): 1433-44.

Received: March 03, 2015

Revised: April 29, 2015

Accepted: May 20,2015

(C) Stewart et al.; Licensee Bentham Open.

This is an open access article licensed under the terms of the (https://creativecommons.org/licenses/by/4.0/legalcode), which permits unrestricted, noncommercial use, distribution and reproduction in any medium, provided the work is properly cited. 